Sign Systems Studies 35.1/2, 2007

\title{
Gathering in Biosemiotics 6, Salzburg 2006
}

\author{
Günther Witzany, ${ }^{1}$ Maricela Yip ${ }^{2}$
}

The sixth Gathering in Biosemiotics was organized in Salzburg, Austria, by Günther Witzany and Wolfgang Hofkirchner. ${ }^{3}$ Fifty-eight scientists from various scientific fields like philosophy, systems theory, semiotics, linguistics, semantics, mathematics, statistics, psychology, physics, medicine, biochemistry, embryology, molecular biology, microbiology, cell biology, genetics, epigenetics, evolutionary biology, zoology, mycology and botany participated.

\section{Introduction}

Biosemiotics is a transdisciplinary science which investigates sign processes (semioses) within and among living organisms with theoretical and empirical studies. The signs used underlay three levels of semiotic rules. Syntactic rules govern combinatorial possibilities, be they physical, chemical, spatial, temporal, or rhythmical. Pragmatic rules govern interactions and interactional contexts like growth, development, defence or mating. Semantic rules depend on their contextual use, i.e. semantics is visible in the specific function of signs which represent their meaning.

Individuals in populations share a common repertoire of signs and rules. This is valid also at the level of cell biology. Dependent on the context of use the same signs and sequences of signs may have different informational content. Therefore it can be understood that from the same genetic dataset it is

\footnotetext{
1 Address: Günther Witzany, telos — Philosophische Praxis, Vogelsangstraße 18c, A-5111-Bürmoos, Salzburg, Austria; e-mail: witzany@sbg.at.

2 Address: Maricela Yip, ICT\&S Center, University of Salzburg, SigmundHaffner-Gasse 18, 5020, Salzburg, Austria; e-mail: maricela.yip@sbg.ac.at.

3 W. Hofkirchner is from the Center for Advanced Studies and Research in Information and Communication Technologies \& Society (ICT\&S), University of Salzburg, Austria.
} 
possible to produce different cell types according to different methylation patterns of the chromosome for different needs.

Biosemiotics investigates not only sign processes within and among cells but also immunological, neuronal or hormonal sign sequences. For many biosemioticians life starts with sign processes and vice versa (Hoffmeyer 1996; Kull 1999; Barbieri 2001; Markoš 2002; Emmeche, Hoffmeyer 2005; Witzany $1993 ; 2000 ; 2006)$. Until recently biosemiotic terms were viewed as mere metaphorics by molecular biology, genetics, ecology and evolutionary biology because of the conviction that they could be replaced completely by chemical and physical descriptions. The hardly bridgeable gap between chemical-physical and biosemiotic descriptions allow biosemiotics a clear distinction between life and non-life or as Howard Pattee (2005: 321) said: "Life is distinguished from the nonliving world by its dependence on signs". Biosemiotics therefore broadens our understanding of all biological processes. Life processes depend not solely on physical/chemical changes but additionally on communication and information processing which are determined by semiotic rules which are coherent with but different to natural laws. Their success or failure decides the growth, development, disease or death of all living beings.

\section{Pre-programme: Biosemiotics in transdisciplinary contexts}

To give a broader audience the possibility of getting in contact with biosemiotics the organizers Günther Witzany and Wolfgang Hofkirchner initiated a pre-programme, one day before the official start of the Gatherings with experts, in several cases non-semioticians, who presented their theoretical and empirical work with strong relation to biosemiotics.

After the introduction given by Wolfgang Hofkirchner, Jesper Hoffmeyer (Copenhagen, Denmark) opened with an analysis of the work of Gregory Bateson, one of the forerunners of biosemiotics. Frantisek Baluska (Bonn, Germany) reported about "neurobiological" communication in plants: with synapse-like cell-cell-communication plants can use a kind of signal-transmission system which enables them to develop a great variety of behaviours also in their sessile lifestyle. Peter Barlow (Bristol, England) explained a model (L-systems) of constructing algorithms which could represent succession states recognized as proceeding from the two 'pillars' of living organization - metabolism and morphology. His model proposed to look at the semiotic contexts of these "living" algorithms. Randy Jirtle (Durham, USA), one of the pioneers in epigenetic research, reported on his breakthrough research success when they detected genomic sequences which are inherited either paternally or maternally. So they could prove that special parental feeding behaviours can influence and change genomic expression 
patterns of descendents. Kalevi Kull's (Tartu, Estonia) contribution showed a common feature of semiotics and biosemiotics: the ability to study qualitative diversity. Biosemiotics could be a new approach for better understanding of semiotic selves in non-human living beings and their communicative identities covering all biological species, social groups and even perceptual categories. Günther Witzany's (Salzburg, Austria) talk focused on recent research on virology. So-called "junk-DNA" which has been thought to be useless remnants of former evolutionary stages and which represent $97 \%$ of the human genome are now being recognized as higher order regulatory domains which regulate transcription, replication, repair and recombination in all detailed steps and substeps. They descended most likely from viruses with persistent non-lytic lifestyle which use genomes of cellular life forms as a comfortable life habitat and organize host genome syntax according to their needs and those of their host organisms.

In the afternoon Nikolaus Bresgen (Salzburg, Austria) demonstrated the complex phenomenon of apoptosis, that success or failure of all cell signalling processes depends on the context in which these signals are used. Erich Hamberger (Salzburg, Austria) focused on some transdisciplinary remarks of biosemiotics in the relationship of word, sign and signal dependent on their (bio-) cultural background in which this relation is common use. Therefore also on the cellular level similar functions can be analysed like transduction, transmission and signalling. Klaus Fuchs-Kittowski (Berlin, Germany) developed a non-mechanistic but semiotically inspired informational theoretic perspective on biotic information processing especially for some ethical aspects. Donald Favareau (Singapore) looked at animal sensing, acting and knowing and suggested the Peircian levels of signs (icon, index, symbol) to be appropriate tools for investigating animal perceptual worlds and to reconstruct a human knowledge generating hierarchy of sign relations. Albert Duschl (Salzburg, Austria) referred to the evolution and mechanisms of mixed analogue/digital information processing in living cells according to an information theoretical perspective which looks at living organisms as information processing "living computers". John Collier (Durban, South Africa) suggested a systems biological approach for a better foundation of biosemiotics. According to the model of Robert Rosen's systems theory, Collier suggested to understand certain living processes in a mechanistic perspective rather than needing semiotic analyses. Ingolf Schmid-Tannwald (Munich, Germany) tried to integrate semiotic aspects in a systems theoretical realm.

\section{Programme}

The main programme of the Gathering was separated into seven sections. We will report selected examples. The starting section was Semantics in 


\section{Günther Witzany, Maricela Yip}

Biosemiotics with contributions on the emergence and generation of meaning functions in living entities. Marcello Barbieri (Ferrara, Italy) started with his model of the emergence of the genetic code as being independent of contextual needs whereas the later steps of sequence order and the emergence of a great variety of other biotic codes have been context-dependent. In the section Methods of Biosemiotics four talks suggested how biosemiotic methodology could be developed. Kalevi Kull (Tartu, Estonia) presented a clarifying overview on methodological presuppositions and differentiations of biosemiotics in contrast to non-biosemiotic perspectives. Peter Harries-Jones (Toronto, Canada) suggested the installation of an editorial group for biosemiotics at Wikipedia. In the section Semiotics in Biosemiotics Donald Favareau (Singapore) suggested in his contribution to choose a unique vocabulary for biosemiotic studies in using the Peircian icon, index and symbol.

The second day of the official programme started with six talks in the section Applied Biosemiotics with Argyris Arnellos (Athens, Greece) with a biosemiotic analysis of the functions of the serotonin-complex. Almo Farina (Urbino, Italy) presented his eco-field hypothesis and its relevance for humans to understand resources and functions of cultural landscapes. Toshiyuki Nakajima (Matsuyama, Japan) spoke about exchange of genetic elements and their relevance for evolutionary processes. Günther Witzany (Salzburg, Austria) developed an applied biosemiotics of fungi for the first time and gave an overview about all levels of rule-governed sign-mediated interactions within and among fungal organisms. In the afternoon a broader section focused on Biosemiotics and Information Theory. In several contributions different concepts were presented of the term "information" and its relation to biosemiotics. Pierre Madl (Salzburg, Austria) and Maricela Yip (Salzburg, Austria) demonstrated recent results of research on bio-photonics and its relevance for a non-linear view of living processes.

The last day started with the session on Evolution, Development and Sign Functions. Marcella Faria (São Paulo, Brazil) reported about sign-processes in metabolism, cell-cycles, cell-development, neuronal communication and the immune-system. Randy Jirtle (Durham, USA) demonstrated the predictability of disease susceptibility depending on epigenetic induced changing expression patterns of the genetic code which have been changed by different nutritional behaviour. Mario Gimona (Santa Maria Imbaro, Italy) presented his concept of protein linguistics as a grammar for protein assemblies which could be a synergetic concept in the field of applied biosemiotics. The afternoon session focused on Biosemiotics and Mind Models with various concepts of consciousness, mind and language. Robert Logan (Toronto, Canada) introduced a new definition of "information" which clarified the interdependence of the emergence of languages and cultures in non-human living nature as well as in human life. 


\section{Summary}

This congress showed clearly that the great variety of disciplines which have been represented by the participants could focus easily on diverse aspects of biotic sign processes. This seemed to be a unifying perspective in contrast to other disciplines which are less able to develop a common repertoire of methodological, theoretical and empirical realms of investigations. The exchange of concepts, ideas, opinions and perspectives was less dogmatic and more transdisciplinary which was expressed also by leading biologists. This could lead to a new perspective on living nature and therefore to changing the relationship of humans and non-human life in general and in detail. The full programme and all of the abstracts can be downloaded at the congress website. $^{4}$

\section{References}

Barbieri, Marcello 2001. The Organic Codes: The Birth of Semantic Biology. Ancona: PeQuod.

Emmeche, Claus; Hoffmeyer, Jesper 2005. Code-duality and the semiotics of nature. Journal of Biosemiotics 1: 27-64.

Hoffmeyer, Jesper 1996. Signs of Meaning in the Universe. Bloomington: Indiana University Press.

Kull, Kalevi 1999. Biosemiotics in the twentieth century: a view from biology. Semiotica 127(1/4): 385-414.

Markoš, Anton 2002. Readers of the Book of Life: Contextualizing Developmental Evolutionary Biology. Oxford: Oxford University Press.

Pattee, Howard H. 2005. The physics and metaphysics of biosemiotics. Journal of Biosemiotics 1: 223-238.

Witzany, Günther 1993. Natur der Sprache - Sprache der Natur: Sprachpragmatische Philosophie der Biologie. Würzburg: Königshausen und Neumann.

- 2000. Life: The Communicative Structure. Norderstedt: Libri Books on Demand.

- 2006. The Logos of the Bios 1: Contributions to the Foundation of a Threelevelled Biosemiotics. Helsinki: Umweb.

4 See http://www.biosemiotics2006.org/. 
